\title{
Normal pattern and physiological significance of mitral valve flow velocity recorded using transseptal directional Doppler ultrasound catheterization
}

\author{
D. Kalmanson, A. Bernier, Colette Veyrat, S. Witchitz, C. H. Savier, and P. Chiche \\ From the Departments of Cardiology, Hopital Tenon and Fondation Ophtalmologique A. de Rothschild, Paris, \\ France
}

In ro cardiac patients in whom an organic lesion of the mitral valve was excluded by standard investigation procedures during which a diagnostic transseptal catheterization for pressure measurements in the left heart was performed, the authors placed a directional Doppler ultrasonic catheter tip velocimeter at the site of the mitral ring and recorded the mitral flow velocity traces. The pattern of these normal curves is presented and a physiological interpretation proposed. The relation between the mitral flow velocity and flow volume curves is discussed in the light of present experimental data on mitral valve flow velocity profiles and variations in size of the mitral orifice. The authors conclude that the flow velocity curves obtained by the Doppler technique constitute a valid physiological reference system for the study of the mitral valve flow velocity tracings that can be recorded in the various forms of mitral valve disease.

The currently used investigative procedure for diagnosing mitral valve disease, such as intracardiac pressure measurements, selective angiocardiography, dye dilution methods, or echocardiography are not capable of demonstrating the pattern of pulsatile flow through the mitral valve. We have shown (Kalmanson, Derai, and Novikoff, I97I) the feasibility of obtaining such information at the tricuspid valve by catheterizing the right heart with a directional Doppler ultrasonic catheter, and have proposed a physiological interpretation for the normal tricuspid valve flow velocity curve. The successful application of this technique for diagnosing tricuspid valve disease using a pattern recognition method prompted us to study whether a similar procedure using the transseptal route could help in diagnosing and assessing the severity of mitral valve disease.

In this report we will consider the normal flow velocity pattern and its physiological interpretation. In our next report we will consider the abnormal flow velocity patterns in mitral valve disease and their diagnostic value. A combined presentation of the methods will, however, be given in this report, for the purpose of clarity.

\section{Subjects}

In order to determine the flow velocity pattern of the normal mitral valve, we studied a control group of ro patients, 4 women and 6 men, ranging in age from 25 to 59 years, in all of whom an organic mitral valve lesion, Received ro July 1974. and in particular mitral regurgitation, was excluded by the classical investigation procedures. The diagnosis and the clinical presentation of these patients are briefly summarized hereunder, and their haemodynamic data are presented in the Table. All save one (Case 4) were in sinus rhythm.

Case I: Patent foramen ovale, with an otherwise normal heart.

Case 2: High atrial septal defect with moderate left-toright shunt. Quiet systolic murmur at second left intercostal space, split second heart sound. Chest film showed slight enlargement of the heart. Electrocardiogram showed incomplete right bundle-branch block.

Case 3: Chronic constrictive pericarditis of tuberculous origin. Pericardial rub. Chest film showed considerable enlargement of the heart. Electrocardiogram indicated raised ST segments in all leads. Enlargement of the liver, oedema of the ankles. Typical dip-plateau pattern disclosed at right heart catheterization.

Case 4: Chronic non-constrictive pericarditis, with chronic bronchitis. Dyspnoea on exertion; complete arrhythmia. Chest film showed enlargement of the heart. Electrocardiogram indicated flattening of the $T$ waves in all leads. Normal haemodynamic data.

Case 5: Cardiac failure of unknown origin. Sinus rhythm, protodiastolic gallop. Enlargement of the liver, oedema of the lower limbs. Chest film showed moderate enlargement of the heart. Electrocardiogram showed combined overload of the ventricles. Normal PR interval.

Case 6: Normal heart with an abnormal shadow in the lung or $x$-ray suspicious of an intrapulmonary arteriovenous fistula.

Case 7: Obstructive cardiomyopathy. Mesosystolic mur- 
mur at the apex, 4th heart sound. Normal chest film. Electrocardiogram showed prolonged $P R$ interval $(0.28 \mathrm{~s})$. Pattern of pseudonecrosis in standard leads. Left atrial overload. Carotid pulse tracing showed typical mesosystolic notch, enhanced by the inhalation of amyl nitrite.

Case 8: Obstructive cardiomyopathy. Mid- and endsystolic murmur at the 4 th left intercostal space. Important enlargement of the heart on the chest film. Electrocardiogram showed complete left bundle-branch block. Typical notch on the carotid pulse tracing. Cardiac failure. The diagnosis was confirmed at necropsy.

Case 9: Left ventricular failure of unknown origin. Mid-diastolic gallop. Electrocardiogram indicated second-degree atrioventricular block. Chest film showed moderate enlargement of the heart.

Case 10: Pure aortic regurgitation. Diastolic and systolic murmurs. Blood pressure was $170 / 30 \mathrm{mmHg}$ (22.5/ $4 \mathrm{kPa}$ ). Chest film showed considerable enlargement of the heart. Electrocardiogram showed prolonged PR interval. Left ventricular overload.

\section{Methods}

All patients underwent a routine diagnostic catheterization of the left heart using the transseptal route and the Telco ${ }^{1}$ manometer, according to Forman's technique (Forman, Laurens, and Servelle, 1962). Both atrial and ventricular pressures were recorded successively or ${ }^{1}$ Telco, 94 - Gentilly, France. simultaneously allowing the measurement of the LA-LV pressure gradient. Cardiac output and mitral regurgitation were measured by the dye (indocyanine green) dilution technique using the Waters ${ }^{2}$ apparatus. Mitral valve area was calculated using the Gorlin formula with correction for any mitral regurgitation which was demonstrated.

\section{Technique}

We used the directional ultrasonic Doppler 7 French catheter velocimeter (Sonicaid BV I80) ${ }^{3}$ either with a normal or a single ceramic orientable catheter tip, the details of which have been reported elsewhere (Kalmanson et al., 1972). The catheter velocimeter measures the instantaneous bloodflow velocity approximately $5 \mathrm{~mm}$ ahead of its tip, and discerns forward and reverse (but not lateral) flow.

The procedure always followed transseptal pressure catheterization during which the mitral area was localized using a pull-back manoeuvre from the left ventricle to the left atrium. After the pressure catheter had been removed, the sheath leading through the interatrial septum from the right atrium to the left being left in situ, the sterile catheter velocimeter was inserted into the proximal orifice of the sheath and advanced to the left atrium. It was then guided under fluoroscopy to the mitral ring. The catheter tip was finally aligned with the direc-

${ }^{2}$ Waters, Rochester, Minnesota, U.S.A.

3 Sonicaid Ltd., Bognor Regis, Sussex.

TABLE Haemodynamic data of patients

\begin{tabular}{|c|c|c|c|c|c|c|c|}
\hline $\begin{array}{l}\text { Case } \\
\text { No. }\end{array}$ & $\begin{array}{l}\text { Age } \\
(y r)\end{array}$ & $\begin{array}{l}R A \text { pressures } \\
(m m H g)(k P a)\end{array}$ & $\begin{array}{l}R V \text { pressures } \\
(\mathrm{mmHg})(k P a\end{array}$ & & Mean & $\begin{array}{l}P A \text { pressures } \\
(m m H g)(k P a)\end{array}$ & $\begin{array}{l}\text { LA pressures } \\
\text { mean } \\
(m m H g)(k P a)\end{array}$ \\
\hline I & 26 & $\begin{array}{l}4 \\
0.5\end{array}$ & $\begin{array}{l}20 / 2 \\
2.6 / 0.3\end{array}$ & & $\begin{array}{l}\text { I0 } \\
1.3\end{array}$ & $\begin{array}{l}27 / 10 \\
3.6 / 1.3\end{array}$ & $\begin{array}{l}7 \\
0.9\end{array}$ \\
\hline 2 & 25 & $\begin{array}{l}2 \\
0.26\end{array}$ & $\begin{array}{c}\text { Low } 36 / 0 \\
4.8 / 0 \\
\text { High } 30 / 0 \\
3.9 / 0\end{array}$ & ed $\begin{array}{r}4 \\
0.5\end{array}$ & $\begin{array}{l}13 \\
1.7 \\
15 \\
1.9\end{array}$ & $\begin{array}{l}30 / 10 \\
3.9 / 1.3\end{array}$ & $\begin{array}{l}3 \\
0.4\end{array}$ \\
\hline 3 & 39 & $\begin{array}{l}\text { Io } \\
T .3\end{array}$ & $\begin{array}{l}30 / 3 \\
3.9 / 0.4\end{array}$ & 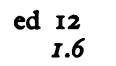 & $\begin{array}{c}14 \\
1.9\end{array}$ & $\begin{array}{l}26 / 10 \\
3.5 / 1.3\end{array}$ & $\begin{array}{l}10 \\
1.3\end{array}$ \\
\hline 4 & 42 & & $\begin{array}{l}17 / 1 \\
2.3 / 0.1\end{array}$ & $\begin{array}{r}\text { ed } 0 \\
0\end{array}$ & $\begin{array}{c}5 \\
0.6\end{array}$ & $\begin{array}{l}18 / 7 \\
2.4 / 0.9\end{array}$ & $\begin{array}{l}4 \\
0.5\end{array}$ \\
\hline 5 & $5 \mathrm{I}$ & $\begin{array}{l}4 \\
0.5\end{array}$ & $\begin{array}{l}45 / 0 \\
5.9 / 0\end{array}$ & $\begin{array}{r}\text { ed } 8 \\
I . I\end{array}$ & 20 & $\begin{array}{l}46 / 20 \\
6.1 / 2.7\end{array}$ & $\begin{array}{c}16 \\
2.1\end{array}$ \\
\hline 6 & 32 & $\begin{array}{l}2 \\
0.3\end{array}$ & $\begin{array}{l}25 / 0 \\
3.3 / 0\end{array}$ & ed $\begin{array}{l}3 \\
0.4\end{array}$ & $\begin{array}{l}8 \\
I . T\end{array}$ & $\begin{array}{l}22 / 8 \\
2.9 / I . I\end{array}$ & $\begin{array}{l}4 \\
0.5\end{array}$ \\
\hline 7 & 38 & $\begin{array}{l}0 \\
0\end{array}$ & $\begin{array}{l}25 / 0 \\
3.3 / 0\end{array}$ & & $\begin{array}{l}6 \\
0.8\end{array}$ & $\begin{array}{l}22 / 9 \\
2.9 / 1.2\end{array}$ & $\begin{array}{l}8 \\
1.1\end{array}$ \\
\hline 8 & 40 & $\begin{array}{l}2 \\
0.3\end{array}$ & $\begin{array}{c}\text { Low } 40 / 0 \\
5.3 / 0\end{array}$ & ed $\begin{array}{r}4 \\
0.5\end{array}$ & & $\begin{array}{l}20 / 1 \mathrm{I} \\
2.7 / 1.5\end{array}$ & $\begin{array}{l}6 \\
0.8\end{array}$ \\
\hline 9 & 59 & $\begin{array}{l}8 \\
I . I\end{array}$ & $\begin{array}{l}38 / 2 \\
5.0 / 0.3\end{array}$ & ed ${ }_{0.6}^{5}$ & $\begin{array}{l}19 \\
2.5\end{array}$ & $\begin{array}{l}35 / 16 \\
4.6 / 2 . I\end{array}$ & 9 \\
\hline ro & 33 & $\begin{array}{l}9 \\
1.2\end{array}$ & $\begin{array}{l}44 / 0 \\
5.810\end{array}$ & ed 12 & $\begin{array}{l}19 \\
2.5\end{array}$ & $\begin{array}{l}42 / 16 \\
5.6 / 2.1\end{array}$ & $\begin{array}{l}16 \\
2.1\end{array}$ \\
\hline
\end{tabular}

RA: right atrium; RV: right ventricle; PA: pulmonary artery; LA : left atrium; LV: left ventricle; BA: brachial artery. Pressures in SI units are given in italics. 
tion of blood flow by adjustment of the proximal end of the catheter or by using the catheter selector, as we have previously described (Kalmanson et al., I972). Recordings were made at the site of, and immediately above the mitral annulus at different points near the centre, the anterolateral, and whenever possible the posteromedial commissures (Fig. I). The traces were recorded during quiet respiration in unanaesthetized patients and inscribed on a four-channel 34 or seven-channel $8 \mathrm{I}$ Mingograf, direct inkwriting recorder, simultaneously with electrocardiogram lead II and frequency selected phonocardiogram at the second left intercostal space. The chart speed was either 25 or $50 \mathrm{~mm} / \mathrm{s}$. The distance between two successive spikes (upper row in the figures) equals I s. Square notches on the trace are irrelevant as far as this text is concerned.

\section{Results}

The use of the Doppler catheter produced no complication apart from transient atrial and ventricular arrhythmias. There was no clotting around the catheter. There was no morbidity associated with the transseptal technique. In 5 patients not included in this report, the procedure failed: in 2, an increasingly severe bradycardia was considered as an absolute indication to withdraw the catheter, and in the 3 others, the catheter tip could not be immobilized satisfactorily.

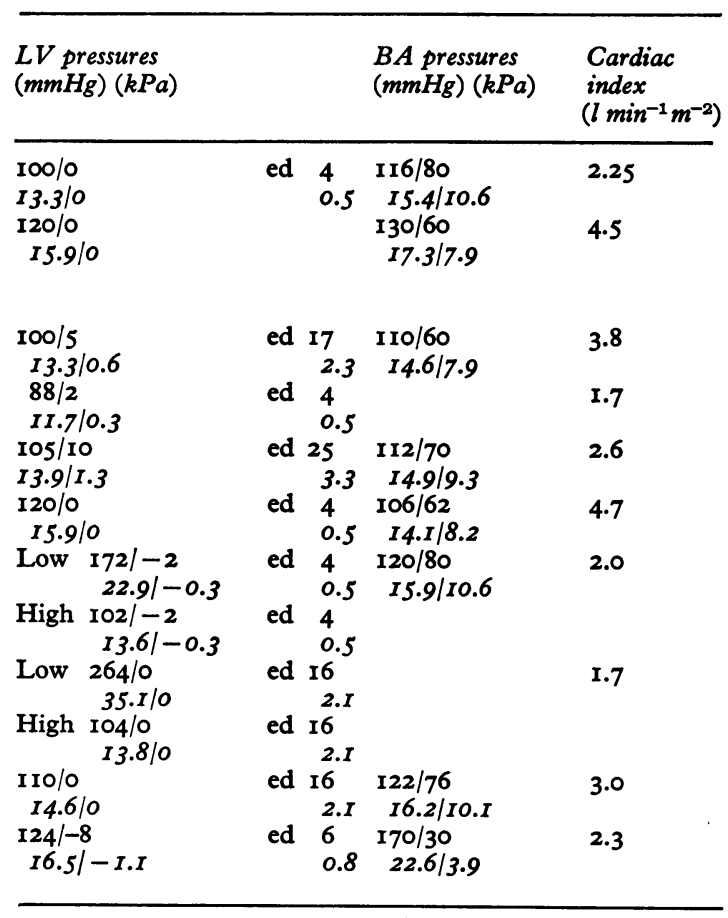

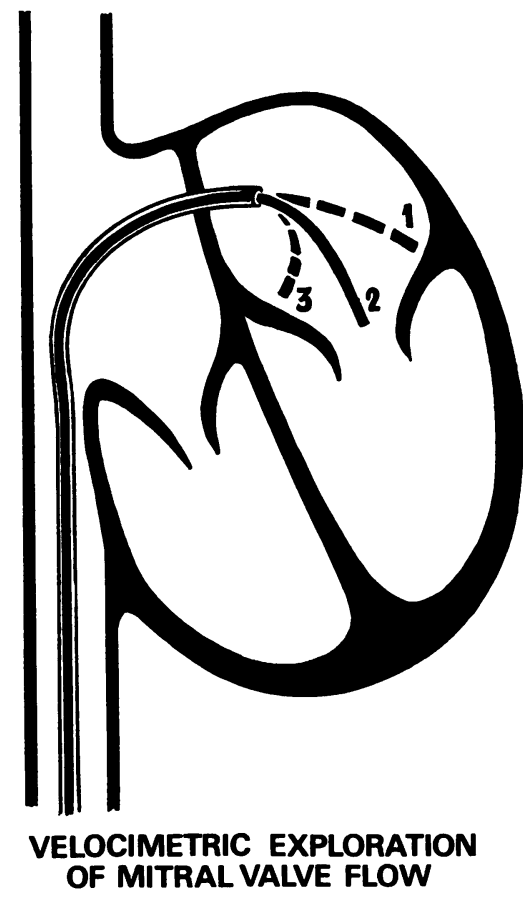

FIG. I Transseptal exploration of the mitral valve annulus. The Doppler catheter is pushed forward into the sheath leading to the left atrium, and its tip is placed under fluoroscopic control at different points of the mitral ring previously identified by a pull-back manoeuvre in the course of pressure catheterization of the left heart. Main points of interest are the centre (2), the anterolateral commissure area $(I)$, and, whenever possible, the posteromedial commissure area (3).

\section{Mitral valve flow velocity curves}

The recorded curves represent the velocity, calibrated in $\mathrm{cm} / \mathrm{s}$, of blood flowing through the mitral valve, at a point situated $5 \mathrm{~mm}$ ahead of the catheter tip. Positive or negative sign of velocities depends on the orientation of the catheter tip with respect to the direction of blood flow. By convention, positive velocities apply to blood flowing from the left atrium into the left ventricle. Negative velocities apply to blood regurgitating from the left ventricle into the left atrium and also to atrial blood pushed back by an upward displacement of a closed and competent mitral valve.

\section{Normal pattern of mitral valve flow velocity}

(Fig. 2, 3, and 4) The curve starts at the beginning of systole with a large, precipitous, and brief negative deflection ( 0.05 to $0.08 \mathrm{~s}$ ), labelled $i c$, synchronous with the first vibrations of the first 
heart sound. Then the trace rises rapidly, rejoins the zero line, and keeps close to the latter throughout the remainder of systole. It often shows a small angulation (B) (Fig. 3 and 4), synchronous with the aortic component of the second heart sound, followed by a short positive, diaphasic, or negative segment, ended by a clear-cut inflection point $(O$, and labelled MO in Fig. 6 and 7). Thereafter, the diastolic part of the curve shows two conspicuous, positive (forward flow) waves: the first early and mid-diastolic labelled D, starting shortly after the aortic component of the second heart sound, triangular in shape with a peak occurring (depending on the heart rate) from 0.13 to $0.20 \mathrm{~s}$ after the second sound, corresponding to maximum values ranging from 20 to $50 \mathrm{~cm} / \mathrm{s}$ depending on the site of recording and on cardiac output. It is followed by an end-diastolic wave, labelled $\mathrm{A}$, also triangular in shape, starting from 0.10 to $0.12 \mathrm{~s}$, and reaching a peak from 0.16 to $0.20 \mathrm{~s}$ after the onset of the $P$ wave. Peak velocities of the $D$ and $A$ waves vary

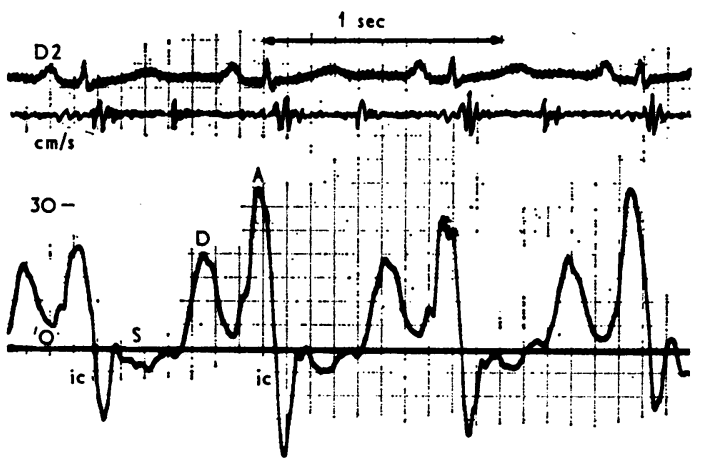

FIG. 2 Normal flow velocity trace of the mitral valve in a patient with a small atrial septal defect (patent foramen ovale). The curve is calibrated in $\mathrm{cm} / \mathrm{s}$. Velocities above the zero line refer to flow passing from the left atrium into the left ventricle, those below the zero line refer to flow directed from the left ventricle toward the left atrium. The curve starts with a brief precipitous negative deflection (ic) lining up with the first heart sound, and indicates either brief regurgitation or an upward displacement of the blood laminae in the left ventricle immediately below the mitral valve during isometric contraction. During the remainder of systole, the $S$ segment runs along the zero line (no flow). Note a minute notch lining up with the second heart sound. Then the curve crosses the baseline (opening of the mitral valve), shows an initial positive, triangular and almost symmetrical $D$ wave, followed by an end-diastolic, larger, $A$ wave, of shorter duration whose timing bears a constant relation to the $P$ wave of the electrocardiogram. inversely, depending on heart rate and respiration. For normal or slow rates the $\mathrm{D}$ wave is larger than the $\mathbf{A}$ wave and inversely for faster rates. In cases with long PR intervals (equal to or greater than $0.20 \mathrm{~s}$ ), the descending limb of the $\mathbf{A}$ wave falls precipitously and overrides the zero line before the occurrence of the first heart sound (Fig. 3).

Other patterns, showing small variations, can be elicited, depending on the site of the recording. The negative initial ic deflection may be absent, or sometimes prolonged for a short period of early systole (Fig. 4).

\section{Discussion and comments}

\section{Technique}

The following points pertinent to the velocimetric Doppler ultrasonic technique have been previously discussed in detail (Kalmanson et al., I969, I97I) and therefore will not be considered here. They include the following.

I) The application of the Doppler principle to back-scattered ultrasound from red blood cells for the measurements of instantaneous bloodflow velocity.

2) The performance and use of the Sonicaid BV 180 catheter-tip velocimeter. It need only be mentioned here that we have shown an almost linear response of the catheter up to velocities of $100 \mathrm{~cm} / \mathrm{s}$.

3) The conditions which might affect the validity of recording within the left heart, such as problems raised by the displacement of the catheter tip caused by bloodflow, the recording of echoes from wall or from valves, and the production of flow disturbances by the presence of a catheter. In the case of the transseptal route, the catheter is normally supported by the bloodflow (and not oriented against it, which makes correct location and immobilization of the catheter easier except in massive mitral regurgitation, where positioning the tip may be somewhat difficult and time consuming).

4) As the method is based on pattern analysis, it is important to use directional velocity sensors, to avoid artefacts which occur in wave forms with nondirectional devices (Mills, I972).

The discussion here will, therefore, be limited to the physiological significance of the recorded curves.

\section{Significance of recorded curves}

Obviously the significance of the blood flow velocity curves, that is their relation to phasic volumetric flow, closely depends on the velocity profile and the value and variations of the area of the mitral annulus. These factors must, therefore, be considered. 


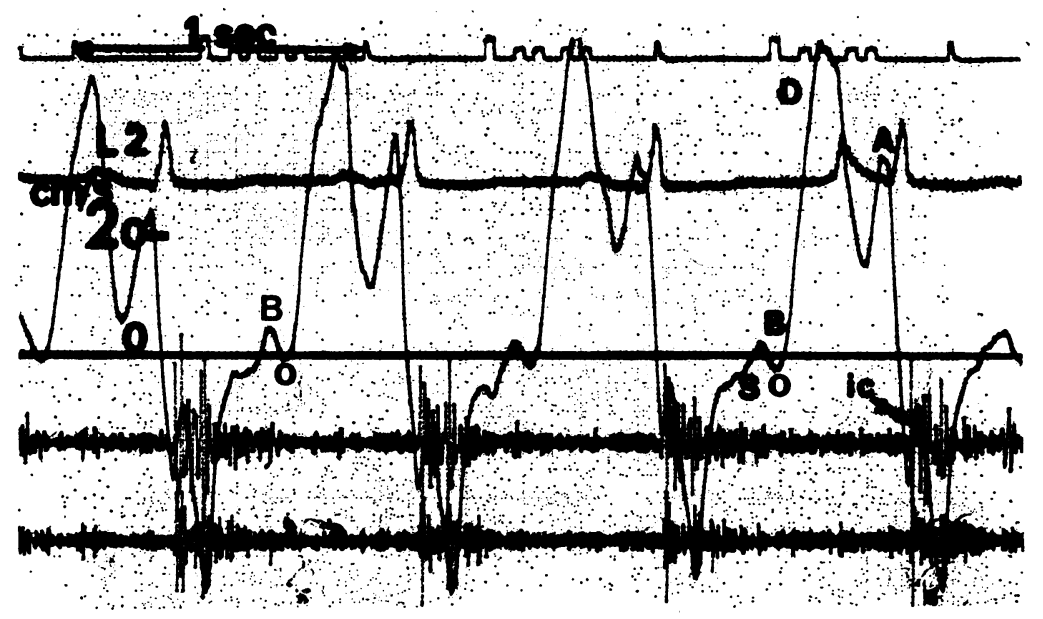

FIG. 3 Normal flow velocity trace in a patient with obstructive cardiomyopathy and without organic lesion of the mitral valve. $P R$ is slightly prolonged $(240 \mathrm{~ms})$. The general pattern is similar to that of Fig. 2. Note the B point lining up with the second heart sound followed by a notch labelled $O$, whose trough occurs 50 ms later, and which is likely to be assigned to the opening of the mitral valve. $B O$ segment represents the isovolumetric relaxation period. At the end of the prolonged $P R$ interval, the trace drops precipitously and overrides the zero line for a short period, indicating a small amount of regurgitation caused by atrial relaxation and the beginning of ventricular contraction being asynchronous.
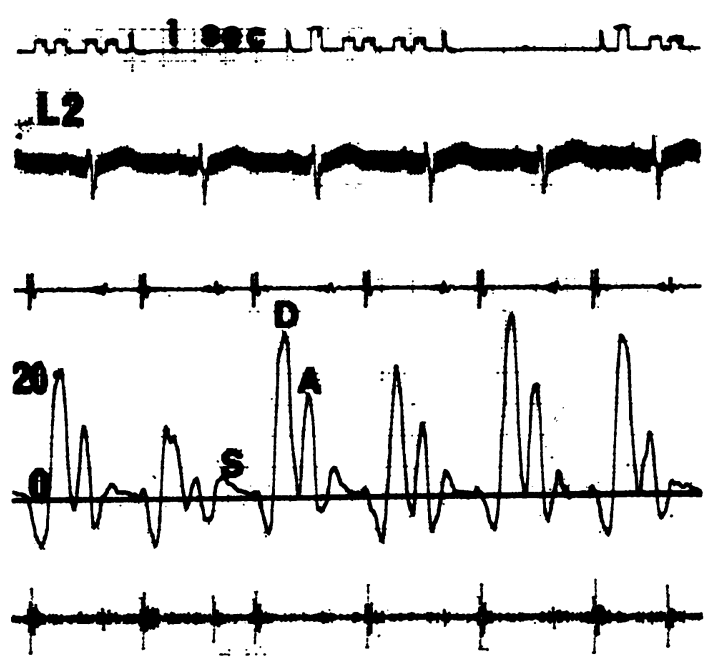

FIG. 4 Normal flow velocity trace in a patient with cardiomyopathy of unknown origin. The initial negative deflection is absent. The remainder of the cycle has the same pattern as the preceding figures. The variations in amplitude of the trace are to be ascribed to small displacement of the catheter tip caused by respiration. Note the small negative wave at end-diastole, just before the first heart sound.
A) Velocity profile of mitral annulus Representativity of the recorded velocity curves is closely related to the pattern of the velocity profile across the mitral annulus. Taylor and Wade (1969) have derived the flow velocity curve from the pressure gradient measured between an upstream and a downstream pressure transducer, at various distances from the valve cusps across the mitral ring. They found no significant changes in the flow velocity at distances from the valve cusps greater than $2 \mathrm{~mm}$. They concluded that the velocity profile across the mitral valve region was probably flat, with a zone of high shear adjacent to the valve surface. It might, therefore, be deduced from this conclusion that the velocity pattern recorded using the Doppler catheter is not influenced by the position of the catheter tip, except when the latter is placed very close to the cusps.

B) Relation between mitral valve flow velocity and flow rate curves Our velocity tracings offer a consistent and striking similarity in pattern and timing with phasic flow curves obtained by other authors using electromagnetic cuff flowmeter probes surgically implanted in animals at the site of the mitral ring (Nolan et al., 1969; Yellin et al., 1970; Folts, Young, and Rowe, I97I; Laniado et al., 
1973). Both types of tracing show similar components, namely the initial systolic negative deflection, the systolic segment along the zero line, and positive waves during early diastole and end-diastole. Only Nolan's phase V corresponding to a minute positive wave in early diastole may fail to be positive on our velocity curves.

C) Variations of mitral valve ring area The quantitative relation between flow velocity and flow volume is naturally dependent on the area of the mitral ring and the way this varies during the cardiac cycle.

The exact value of the mitral annulus area as it changes throughout the cardiac cycle remains unknown in the present 'state of the art', and therefore the Doppler technique is not yet able to provide a quantitative measurement of transmitral volumetric flow.

Nevertheless, further information can be obtained on flow velocity and volume relations in patients. Tsakiris et al. (197I) have studied the continuous variations in size of the mitral ring area, by filming a series of lead beads sewn to the mitral ring of dogs. They showed that the area steadily increased from the beginning of the isovolumetric relaxation period until the end of the rapid diastolic filling phase, and then decreased consistently by a factor of 20 to 34 per cent of the maximum value throughout atrial and ventricular contraction (Fig. 5). More pre- cisely, they stated that the decrease caused by atrial systole ranged between one-half to two-thirds of the total decrease. Assuming that such data may be transposed to humans, this indicates that the relation between flow velocity and flow rate is certainly not linear, but nevertheless that the estimation of the rate blood flow from the blood flow velocity measurements for a given mitral ring area would be underestimated during the rapid filling phase by a factor less than 34 per cent (and probably much less) and overestimated during the atrial contraction period by a factor of less than 22 per cent, at least in basal conditions of pressure and heart rate.

Representativity of blood flow velocity curves Finally, in the light of these observations (namely the striking similarity of blood velocity, and flow rate curves, the flatness of the velocity profile across the mitral ring, the direction of change, and the limited range of variation in size of the mitral ring), it can be assumed that the flow velocity trace as recorded by the Doppler technique provides valuable information on the timing and the general pattern of blood flow, and, therefore, could be of great clinical significance.

Physiological interpretation of curve The complete similarity of the mitral velocity curves in timing and pattern with those recorded in patients

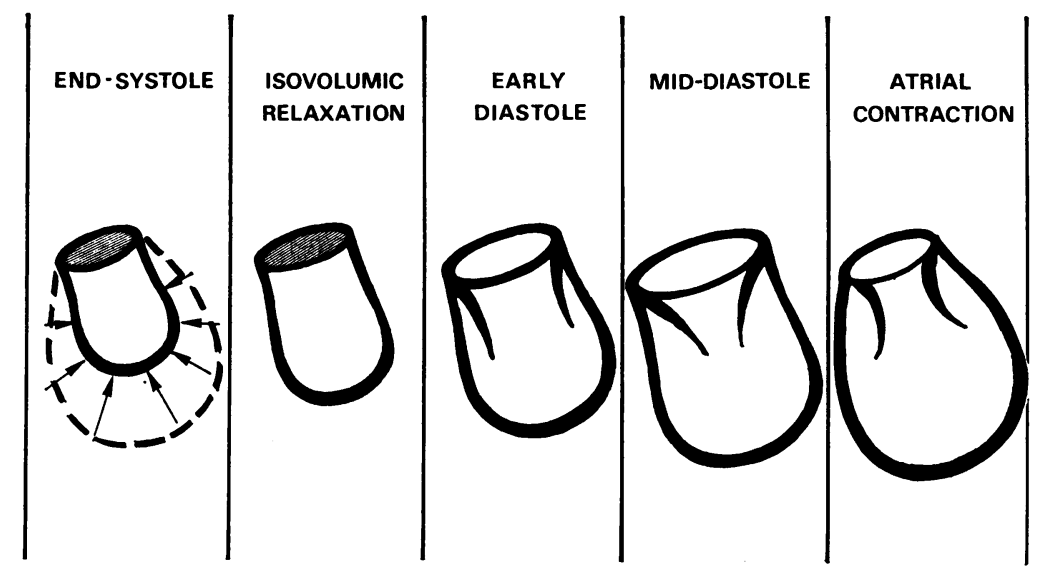

\section{VARIATIONS IN SIZE OF MITRAL VALVE ANNULUS}

FIG. 5 Variations in size of the mitral valve annulus during the cardiac cycle (after Tsakiris et al., 1971). There is a progressive increase in mitral ring area during isovolumetric relaxation, and above all during early and mid-diastole. Before the atrial contraction, the area is maximum. The shrinkage of the mitral annulus is for a large part initiated by atrial contraction, and completed by ventricular systole. The total decrease in the area in dogs was found to range from 20 to 34 per cent of the mid-diastolic maximum value. 
by the same method at the tricuspid valve level (Kalmanson et al., 197I) or in dogs at the level of the mitral valve using the retrograde route (Kalmanson et al., 1972) as well as with blood flow rate curves recorded experimentally using the electromagnetic method (Nolan et al., 1969) allows us to assign the same physiological interpretation to the homologous segments of the velocity and flow curves. These are shown on Fig. 6: the negative initial systolic ic deflection being assigned to the bulging into the atrium of the closed mitral valve during isometric contraction; the $S$ segment corresponding to the absence of flow during systole; the $D$ wave representing the rapid filling wave of the left ventricle; and the $A$ wave representing the enddiastolic filling wave caused by atrial contraction. The MO point represents the very start of the left ventricular filling, i.e. the moment when the mitral valve begins to open. The time interval between the B (synchronous with the aortic component of the second heart sound) and the MO points may, therefore, be considered as measuring the isovolumic relaxation period of the left ventricle. The sole pattern difference between our curve and those of Nolan is the possible occurrence of a negativity during the isovolumic relaxation period.

Relation between left atrial and ventricular pressure, and mitral flow velocity and flow rate patterns

Although we could not simultaneously record pressures and flow velocity, it was possible to compare the timing of some critical events of both phenomena successively recorded, in some patients in whom simultaneous left atrial and left ventricular pressure tracings could be obtained. From our data as well as from those published by other authors (Nolan et al., 1969; Folts et al., 1971; Yellin et al., 1970; Laniado et al., 1973) it is possible to plot such relations (Fig. 7). In particular, points of peak velocity correspond to points of maximum left atrial-left ventricular pressure gradient, involving, however, a small delay. Such a delay is probably caused by the phase lag that has been shown to occur in the following order between pressure, pressure gradient, and flow, in pulsatile flow systems (McDonald, r960; Spencer and Denison, 1956; Yellin et al., 1970). It will be also noted that during the latter half of the initial filling period, though the LA-LV pressure gradient becomes very small or even cancels out, a decelerating flow velocity of significant amplitude persists, because transmitral blood flow is inert (Yellin et al., 1970, Folts et al., I97I).

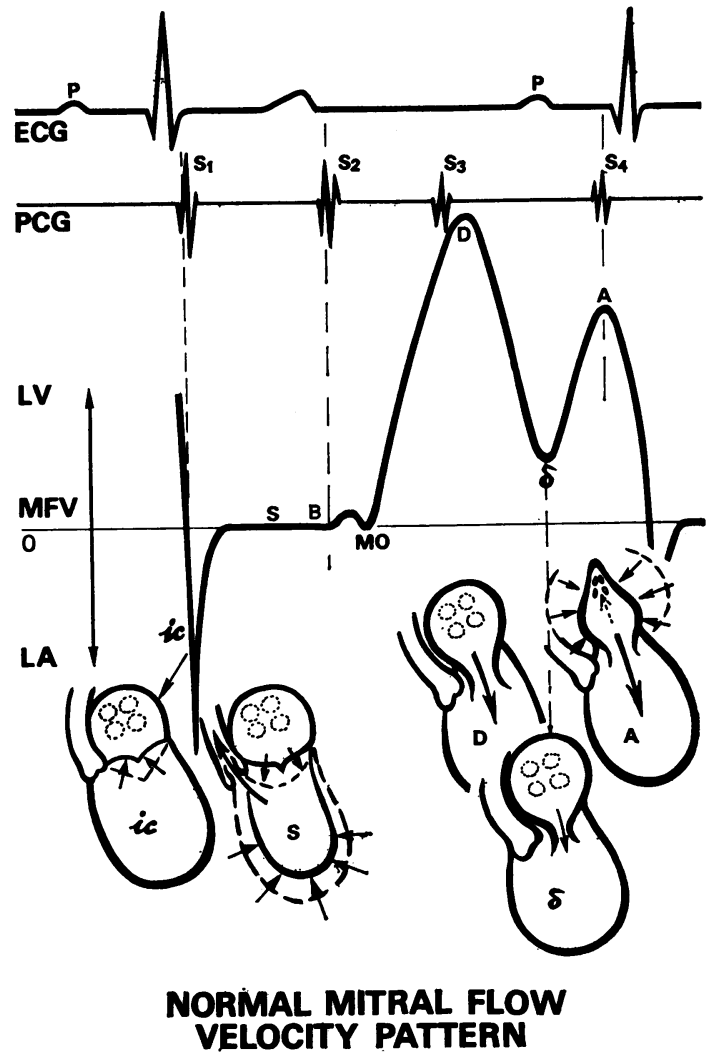

FIG. 6 Physiological interpretation of the normal flow velocity pattern of the mitral valve. The initial negative deflection ic is caused by the bulging of the mitral valve into the left atrium during isometric contraction, provoked by the contraction of the papillary muscles and completing the apposition of the leaflets. Whether it is accompanied by true regurgitation or not is questionable. The $S$ segment along the zero line indicates the absence of flow through the closed mitral floor. The small segment B-MO extending from the notch, synchronous with the second heart sound, to the onset of the $D$ wave delimits the isovolumic relaxation period. The $D$ wave represents the initial diastolic filling of the left ventricle, and the $A$ wave, the end-diastolic filling caused by atrial contraction.

\section{Conclusion}

Although the recorded curves of normal mitral flow velocity provide qualitative rather than quantitative data, they nevertheless may be considered highly representative in terms of timing, direction, and general pattern, of the transmitral blood flow phenomena, and hence as having physiological significance. We may, therefore, conclude that they 


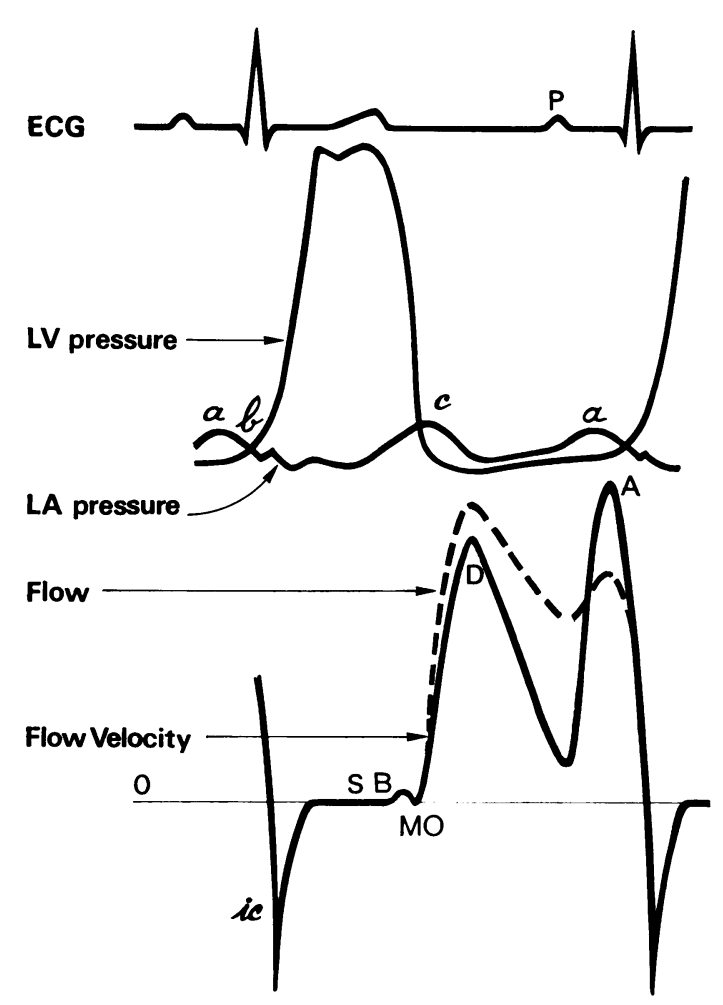

FIG. 7 Relation between left atrial and left ventricular pressures, flow velocity, and estimated flow volume of the normal mitral valve. $L V$ : left ventricle; $L A$ : left atrium; dotted line: mitral valve flow rate; block line: mitral valve flow velocity; ic; isometric contraction deflection; $S$ : systolic component; $D$ and $A$ : initial diastolic and end-diastolic filling waves; $O$ : opening of the mitral valve. Dotted line is the estimated flow volume curve of the mitral valve. The crossing point $b$ of $L A$ and $L V$ pressure curves slightly precedes the onset of the ic negative deflection. The latter takes place during the initial part of the ascending limb of the LV systolic trace. The MO point lines up with the crossing point $c$ at the end of the isovolumic relaxation period. The summit of the $D$ wave lags slightly after the point of maximum LA-LV pressure gradient. Contrary to the flow velocity $D$ wave, the flow volume wave is asymmetrical, the descending limb having a smaller slope than that of the ascending one. This is because of the expansion of the mitral ring area during this period (see Fig. 5). The diastolic $L A-L V$ gradient has been exaggerated for the purpose of clarity. It can be equal to zero during the latter half of the initial period while inflow still persists, because of the property of inertia in the system (Yellin et al., I970). constitute a valid physiological system for the study, by means of a pattern recognition method, of the abnormal mitral valve flow velocity tracings that can be recorded in states of mitral valve disease.

The authors are indebted to Dr. D. Tunstall-Pedoe (London) for his correction of the English translation and his valuable suggestions.

\section{References}

Folts, J., Young, W. P., and Rowe, G. G. (197I). Phasic flow through normal and prosthetic mitral valves in unanesthetized dogs. Fournal of Thoracic and Cardiovascular Surgery, 61, 235.

Forman, J., Laurens, P., and Servelle, M. (1962). Le cathétérisme des cavités gauches au micromanomètre par voie transseptale. Archives des Maladies du Coeur et des Vaisseaux, 55, 6or.

Kalmanson, D., Derai, C., and Novikoff, N. (I97I). Le flux tricuspidien étudié chez l'animal et chez l'homme par cathétérisme vélocimétrique directionnel. Aspect normal, variations physiologiques et applications diagnostiques. Archives des Maladies du Coeur et des Vaisseaux, 64, 854.

Kalmanson, D., Toutain, G., Novikoff, N., and Derai, C. (1972). Retrograde catheterization of left heart cavities in dogs by means of an orientable directional Doppler catheter-tip flowmeter: a preliminary report. Cardiovascular Research, 6, 309.

Kalmanson, D., Toutain, G., Novikoff, N., Derai, C., Chiche, P., and Cabrol, C. (1969). Le cathétérisme vélocimétrique du coeur et des gros vaisseaux par sonde ultrasonique directionelle à effet Doppler. Rapport préliminaire. Annales de Médecine Interne, 120, 685.

Laniado, S., Yellin, E. L., Miller, H., and Frater, R. W. M. (1973). Temporal relation of the first heart sound to closure of the mitral valve. Circulation, 47, 1006.

McDonald, D. A. (1960). Bloodflow in Arteries. Arnold, London.

Mills, C. J. (1972). Measurements of pulsatile flow and flow velocity. In Cardiovascular Fluid Dynamics, Vol. 1, p. 84. Ed. by D. H. Bergel. Academic Press, London.

Nolan, S. T., Dixon, S., Fisher, R., and Morrow, A. (1969). The influence of atrial contraction and mitral valve mechanics on ventricular fillings. American Heart fournal, 77, 784 .

Spencer, M. P., and Denison, A. B. (1956). The aortic flow pulse as related to differential pressure. Circulation $R e$ search, 4, 476.

Taylor, D. E. M., and Wade, J. D. (I969). Flow through the mitral valve during diastolic filling of the left ventricle. fournal of Physiology, 200, 73P.

Tsakiris, A. G., Von Bernuth, G., Rastelli, G. G., Bourgeois, M. J., Titus, J. L., and Wood, E. H. (197I). Size and motion of the mitral valve annulus in anesthetized intact dogs. Fournal of Applied Physiology, 30, 61 I.

Yellin, E. L., Silverstein, M., Frater, R., and Peskin, C. (1970). Pulsatile flow dynamics across the natural and prosthetic mitral valve. Proceedings, Annual Conference on Engineering in Medicine and Biology. Wellesley Press, Wellesley, Mass., November 15-19.

Requests for reprints to Dr. D. Kalmanson, Fondation Ophtalmologique A. De Rothschild, 29, rue Manin, 75019-Paris, France. 